\begin{tabular}{l} 
Esta obra está sob o direito \\
de Licença Creative \\
Commons Atribuição 4.0 \\
Internacional. \\
\hline
\end{tabular}

\title{
A PLATAFORMA KAHOOT COMO FERRAMENTA EDUCACIONAL DE APRENDIZAGEM NO PROCESSO DE ENSINO APRENDIZAGEM EM FISICA DURANTE AS AULAS REMOTAS DA PANDEMIA DO Sars-coV-2.
}

\author{
Genivaldo Ferreira da Silva \\ Nailza Lima ${ }^{2}$ \\ Celsa dos Santos Albuquerque ${ }^{3}$ \\ Ivací Bonfim Pinheiro ${ }^{4}$
}

\section{RESUMO}

Este trabalho foi desenvolvido com os estudantes do Centro Estadual de Educação profissional e Marcelo Deda Chagas localizada no interior do estado de Sergipe e vimos através deste compartilhar nossa experiencia exitosa com o App Kahoot que nos proporcionou uma dinâmica prazerosa frente as aulas remotas de física nesses tempos de pandemia do Sars-Cov2 e distanciamento social, onde os estudantes tiveram que se adaptar a uma nova realidade. E por meio deste artigo que propomos a síntese da desenvoltura dos estudantes no uso do aplicativo para realizar as atividades do tipo simulado sendo um dos artifícios bem promissores utilizados como suporte para a disciplina de ciências da natureza que é vista como uma das mais desconexa do ponto de vista dos estudantes, visto que para eles, está componente curricular e recheada de cálculos e que não colabora para seu cotidiano. De fato, muito se ouve sobre este fato entre os estudantes, porém com as diversas formas que existe hoje fica a cargo do professor englobar a sua área para entreter os estudantes e com a pandemia não foi diferente. Concluímos, pois, que o interesse dos estudantes frente à novas formas de aprendizagem são inteiramente significativas e que colaboram a curto e longo prazo para o aprendizado dos estudantes do ensino médio em tempos de distanciamento social forçado.

Palavras-chave: Ensino Remoto. Física. Pandemia. Kahoot.

\footnotetext{
1 geni.herreira@gmail.com

2 nlima441@gmail.com

${ }^{3}$ celsaalbuquerque@hotmal.com

4 ivaci18@outlook.com
} 


\section{INTRODUÇÃO}

De fato, desde quando foi pensado em inserido no ensino médio houve rejeição por alguns profissionais da educação e tão repentinamente o ensino remoto tinha tomado conta do território educacional e já vinha sendo de forma minuciosa e o impacto da pandemia do Sars-coV2 só veio acelerar esta modalidade de ensino (hibrido) no ensino médio inserindo uso das tecnologias de informação e comunicação no processo de ensino aprendizagem dos jovens no seu cotidiano. Sabendo do impacto causado pela pandemia nos diversos setores socioeconômico cultural entra em vigor as tão rejeitadas aulas virtuais e todos tiveram que se adaptar a uma nova realidade, tentando se enquadrar a um tipo de ensino que não compete a todos, porém é a realidade que nos convém.

Nisso, busca-se atrelar a todos de uma forma que sejam atingidos e consigam tirar o melhor proveito da situação, a partir daí consigamos atingir os níveis de aprendizados esperados por parte dos estudantes. Essa busca por integrar os diversos modos de aprendizagem fez com que muitos professores tiveram que se reinventar para poder dá conta da demanda de suas disciplinas dentre elas estão as Ciências da Natureza e suas Tecnologias enquadras pela $\mathrm{BNCC}^{1}$.

\footnotetext{
${ }^{1}$ BASE NACIONAL COMUM CURRICULAR
}

Segundo Nogueira (2020) num estudo preliminar realizado pela revista TIC Educação (2019) sobre acesso e uso de tecnologias foi relatado que os alunos do ensino médio usam mais as tecnologias do que os alunos mais novos e os estudo apontam que, entre os alunos do $2^{\mathbf{o}}$ ano do ensino médio, $93 \%$ são usuários de internet. Uso de aplicativos de mensagem instantânea (98\% afirmam realizar esta atividade), uso de redes sociais $(96 \%)$ e pesquisas na internet por curiosidade ou por vontade própria (95\%) são os mais citados. E ainda discute que "Grande parte dos alunos do $2^{\circ}$ ano do ensino médio afirma utilizar a internet também para aprender a fazer algo que não sabia ou que tinha dificuldade em fazer (94\%), ler ou assistir a notícias $(91 \%)$ e ler um livro, um resumo ou um e-book $(65 \%)$. No entanto, enquanto 95\% destes alunos afirmam assistir a vídeos, programas, filmes ou séries na internet, $57 \%$ dizem postar na rede um texto, uma imagem ou um vídeo que ele ou ela fez."

A partir desses dados vimos a necessidade de colocar em prática nos estudos da disciplina de Física nas 3 séries $\left(1^{\mathrm{a}}, 2^{\mathrm{a}}\right.$ e $\left.3^{\mathrm{a}}\right)$ do ensino médio de uma escola técnica de Sergipe o uso de um App para realização de atividade não presencial nesses tempos de pandemia. 
O App intitulado Kahoot é uma plataforma de aprendizado baseada em jogos e que trabalha conteúdos de forma lúdica, podendo ser acessado tanto pelo celular, quanto pelo computador.

Assim, podemos entretê-los durante esse período tornando as aulas remotas mais dinâmicas e atraentes, visto que a desenvoltura e interesse dos alunos era quase nula.

\section{As aulas remotas de física na pandemia do sars-cov2 e o uso do kahoot como estratégia metodológica}

Link do Google Meet, salas virtuais, smartfones, Notebooks e grupos de Whatsapp tem sido as ferramentas necessárias para atual conjuntura do ensino e elas tem servido "muito bem" para tal feito, mesmo que as aulas remotas tem se apresentado de forma muito desconexa em alguns casos e para alguns, mas foi devido a pandemia do Sarscove2 pelo mundo que várias pessoas foram forçadas a moldaremse as tecnologias, nisso, mexer em um simples smartfone tornou-se tarefa complicada se fazer, mas não difícil de se compreender, recorrendo-se a tutoriais das mais diversas formas nas plataformas de vídeos para ensinar/aprender como the dar com essa nova fase do aprendizado que até então causava resistência, e frente a isso a reviravolta tem ocorrido culminando na percepção de que estamos todos envoltos a

era tecnológica e que foi preciso isso acontecer para podermos nos "adaptar" ou porque não dizer aceitar que isso seria um dia possível. Trabalhos remotos já existiam, e surgiram com mais precisão principalmente no meio educacional, digamos que $100 \%$ de forma tão repentina devido ao distanciamento social, levando a novas formas de pensar, estudar e se reunir para debater um determinado assunto, forçando professores e alunos a aceitação do ensino online, como diz Lagarto et al (2020).

\begin{abstract}
"O ensino online de emergência caracteriza-se por uma separação física entre o aluno e professor, separação essa que não foi planejada e que resulta de uma situação de emergência. A tendência, nestes casos, é de transportar para a distância os conteúdos e o formato das aulas presenciais, e manter os alunos num regime de aulas síncronas e de acordo com os horários estabelecidos para as aulas presenciais".
\end{abstract}

E que tem se tornado um desafio, mais um que os professores encontram para se adequar a realidade que lhe são impostas muitas vezes dentro do campo educacional. Daí, surge, a reflexão feita por Nogueira (2020) que:

Necessidade de distanciamento
social na pandemia mostrou
importância do acesso à internet e
a computadores para escolas,
professores e estudantes. Ensino 
híbrido terá de passar a fazer parte da realidade da educação pública após a quarentena.

É nesse panorama que nós agrupamos as plataformas de ensino ditas síncronas (programas virtuais de videoconferência) e assíncronas onde se podem armazenar materiais ( Power Points, documentos, vídeos em LGP, avisos, entre outros materiais de apoio) para o aluno consultar e estudar, e onde se podem disponibilizar e fomentar espaços de trabalho colaborativo. Aos professores cabe também a necessidade da busca de novas estratégias de estudo para tornar suas aulas mais prazerosas e atraentes "se virando como pode", depara-se com os jogos e plataformas virtuais para isso acontecer. Descobrindo nas metodologias ativas que esta seria a sua única opção nesse tempo de distanciamento social. Nesse sentido o professor busca as melhores formas de fazer com que suas aulas sejam proveitosas trazendo o estudante a inteirar-se dos contextos propostos pelas disciplinas.

Silva et al. (2018) destaca-se que o jovem contemporâneo não pode mais permanecer confinado numa sala de aula, na qual o professor utiliza exclusivamente pincel e quadro branco. Este jovem que já nasceu num mundo imerso nas TDIC, sendo, portanto, nativo digital (PRENSKY, 2001), tem características próprias preferindo imagens a textos, e faz uso com facilidade da linguagem iconográfica. Dessa forma, o aprendiz da atualidade precisa de um ambiente, no qual o professor faça uso de metodologias ativas, utilizando recursos proporcionados pelas tecnologias digitais, com a finalidade de proporcionar motivação extrínseca e intrínseca”.

Defendendo a ideia de que a interação e percepção de que as metodologias ativas e os jogos digitais são os atributos que trazem o aprimoramento de ideias inovadoras que se enquadram nesse perfil e que trazem o prazer de aprender frente ao monótono é que surge as plataformas de games atrelado ao ensino e aprendizagem de alguma forma especifica para que haja compreensão e aproveitamento do é proposto nas atividades à distância e nesse sentido sabemos que selecionar um software educacional e inseri-lo nas atividades de sala de aula uma não é tarefa fácil para alguns. No entanto, é preciso criar espaços de aprendizagem, que os estudantes se apropriem das novas metodologias de ensino associadas aos recursos digitais, tais como os objetos de aprendizagem (OA), ambientes virtuais ou softwares (SILVA et al., 2015)

Cabe ainda salientar, que esses materiais educacionais estejam adequados ao desempenho dos aparelhos dos estudantes, visto que muitos tem relatado que a quantidade de material excede o limite 
de memória acessivo causando transtornos e muitas vezes a evasão escolar promovida ainda pelo distanciamento social e o acesso à internet corrobora para desistência de muitos estudantes e é comprovada na fala da coordenadora da pesquisa TIC Educação, Daniela Costa:

"Apesar de 83\% dos alunos de escolas urbanas serem usuários da internet, há muita desigualdade nesse acesso. Temos, por exemplo, $18 \%$ dos estudantes que acessam exclusivamente a internet pelo celular, sem uso de qualquer outro dispositivo". "Muitas vezes esse celular é compartilhado entre os familiares e o aparelho, quase sempre, não comporta instalação de aplicativos e não há espaço para

\section{METODOLOGIA}

Quanto à abordagem, a metodologia utilizada foi de natureza qualitativa, por se mostrar mais adequada para o tipo de situação que nos convinha. Os instrumentos utilizados para coleta de dados foram observação e questionários online na plataforma Kahoot na modalidade Quizzes. As atividades foram desenvolvidas no final de cada mês sendo que sua utilização surgiu como uma alternativa frente a reclamação da quantidade de atividades propostas pelas disciplinas e que os alunos não estavam dando conta, ficando acumulado e não sendo sintetizada pelos estudantes. Daí, a fim de proporcionar um alivio nas demandas e obter um rendimento mais armazenamento de conteúdo." (Jornal Fato.com.br; jul. 2020).

De fato, é justamente isso que ocorre com a maioria dos estudantes de todo Brasil e acreditamos que é nesse intuito que colaboramos para que os estudantes possam nessa reinvenção pedagógica do processo didático absorver de maneira lúdica os conhecimentos necessários a partir desse aplicativo, podendo ajudá-los de forma prazerosa no ensino remoto e tão necessário atualmente mais especificadamente na área de Física, considerada uma das mais temidas das ciências da natureza e suas tecnologias.

frente a nossa realidade, é que surgiu a oportunidade de utilizá-lo com os alunos da escola técnica estadual numa cidade do interior do estado de Sergipe fazendo simulados virtuais a cada final de mês. A recepção foi a mais promissora possível, propiciando o interesse dos estudantes e aqueles mais interessados em internet e em atividade virtual, se engajando muito bem no "novo" frente ao que disciplina poderia oferecer.

Optamos por apresentá-los a "nova" ferramenta e usá-la nos moldes off-line devido aos fatores de falta de internet ou outros problemas relacionados a isso, repercutindo melhor nas atividades propostas pelo professor. 
O uso do APP nas aulas remotas de física

O App KAHOOT é de origem norueguesa, sendo uma ferramenta tecnológica interativa que incorpora elementos utilizados no design dos jogos para engajar os usuários na aprendizagem. Segundo consta, para alguns teóricos ele serve de proposta para proporcionar experiências envolventes de aprendizado tanto dentro e quanto fora das salas de aula. Uma das características dessa ferramenta é despertar a curiosidade e o envolvimento dos estudantes digitais em experiências para impactar positivamente sua performance de aprendizagem (GAZOTTI-VALLIM; GOMES; FISCHER, 2017).

O Kahoot possibilita a criação de quatro tipos de atividade e optamos por escolher a que mais convinha com a realidade dos estudantes.

Apesar de muitos sentirem dificuldades de acesso o app se apresentava no idioma de língua inglesa (apesar que ele pode ser modificado para o português) e alguns rejeitarem a ferramenta ele foi muito bem aceito pela maioria, corroborando de forma mais promissora para os simulados propostos na disciplina de Física e facilitando o entendimento dos jovens frente as questões propostas para assimilação de conteúdo estudado no ensino remoto.

De acordo com o que apuramos, numa pesquisa realizada sobre a utilização do Kahoot nas aulas de Física observamos que os resultados se apresentaram bem proveitosos como podemos observar nas respostas dos alunos das 3 séries como veremos a segui nos resultados $\mathrm{e}$ discussões. Abaixo temos o quantitativo de participantes no simulado realizado: 


\section{Quantitativo de participantes no 10 Simulado de Física usando o app KAHOOT}

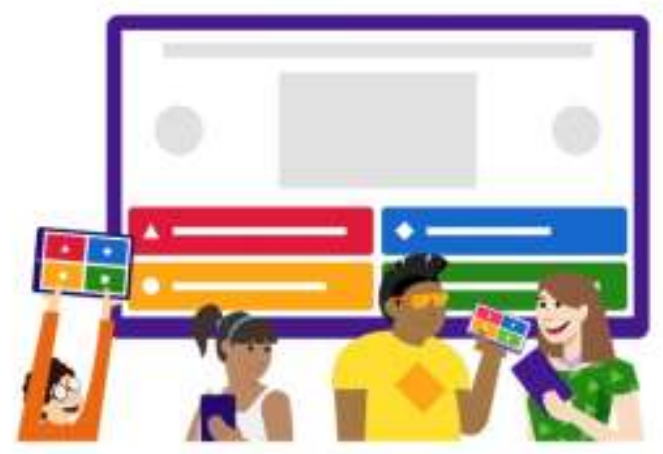

Fonte: Autoria própria.

Quadro 2: Análises das $1^{\mathrm{a}}, 2^{\mathrm{a}}$ e $3^{\mathrm{a}}$ séries.

1올ies: St, Mecânica e Química

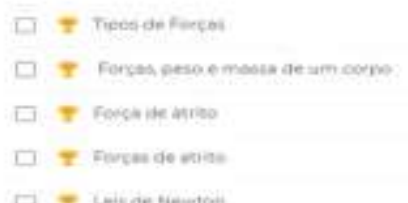

Aug 12 2090 $2020 \mathrm{~nm}$

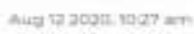

Aug 12 2000

Aug 12 acวo, yave arts

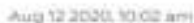

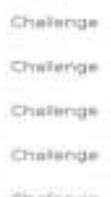

$-5 \quad \vdots$

2aㅡ séries St e PG

\begin{tabular}{|c|c|c|c|}
\hline [ & Avg 72002.1048 am & Chatienge & 45 \\
\hline$\square \mp$ Ondes 2 & Aug 02000.10 .45 am & Consterye & 51 \\
\hline & Aug 12:2020.1099 am & Gialenge & 54 \\
\hline
\end{tabular}

3a Séries St e PG

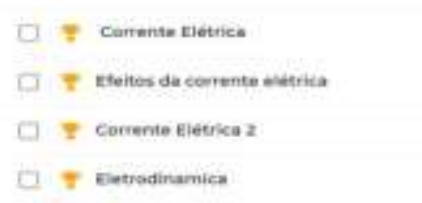


Rev. Científica Evidência, Maceió, v. 3, n.1, p. 108-124, out/dez, 2020

Quadro 3: Resultado com a porcentagem dos 10 primeiros nas $1^{\mathrm{a}}$ séries.

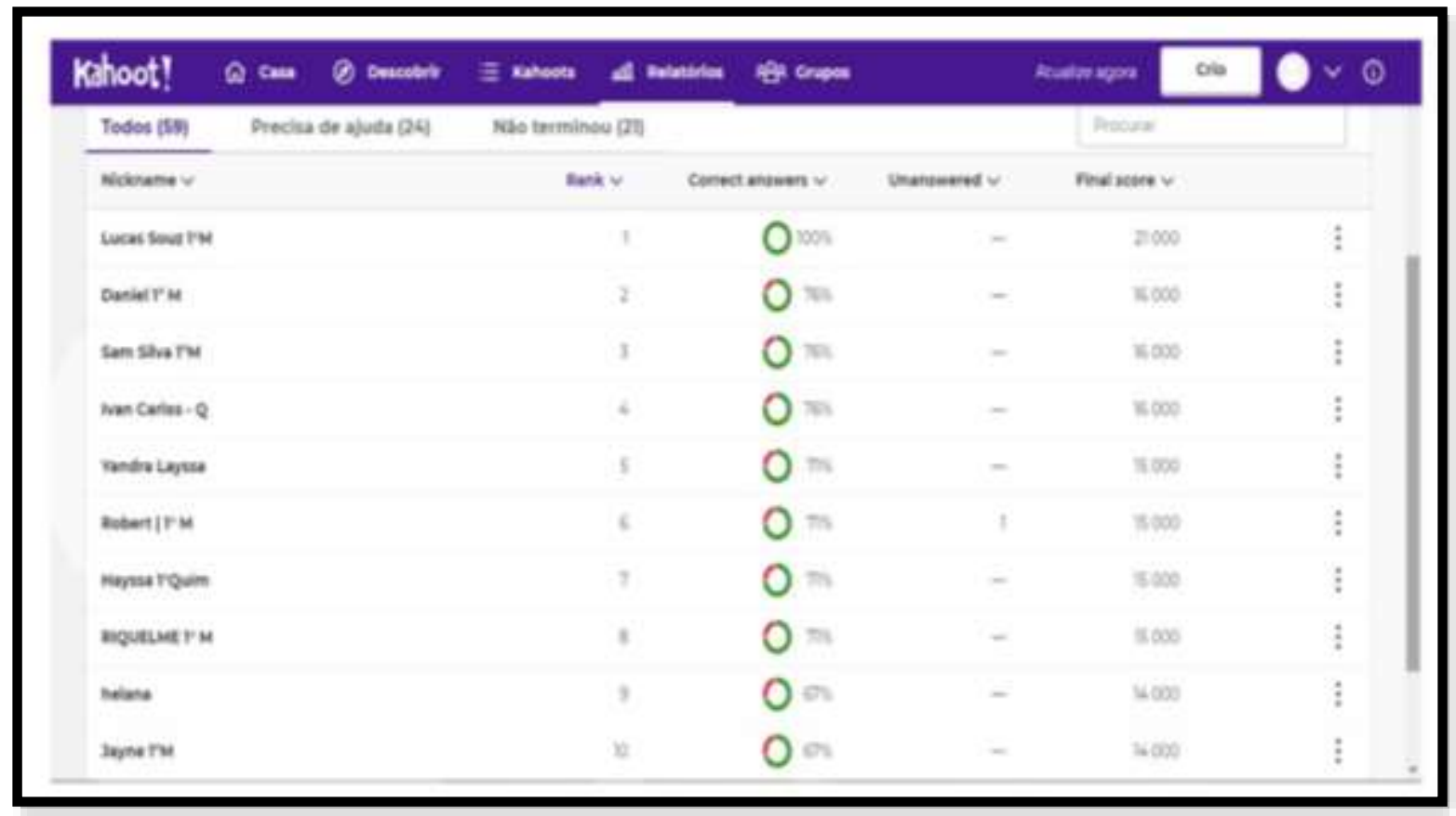

Fonte: Autoria própria.

Quadro 4: Resultados com a porcentagem dos 10 primeiros nas 2a Séries.

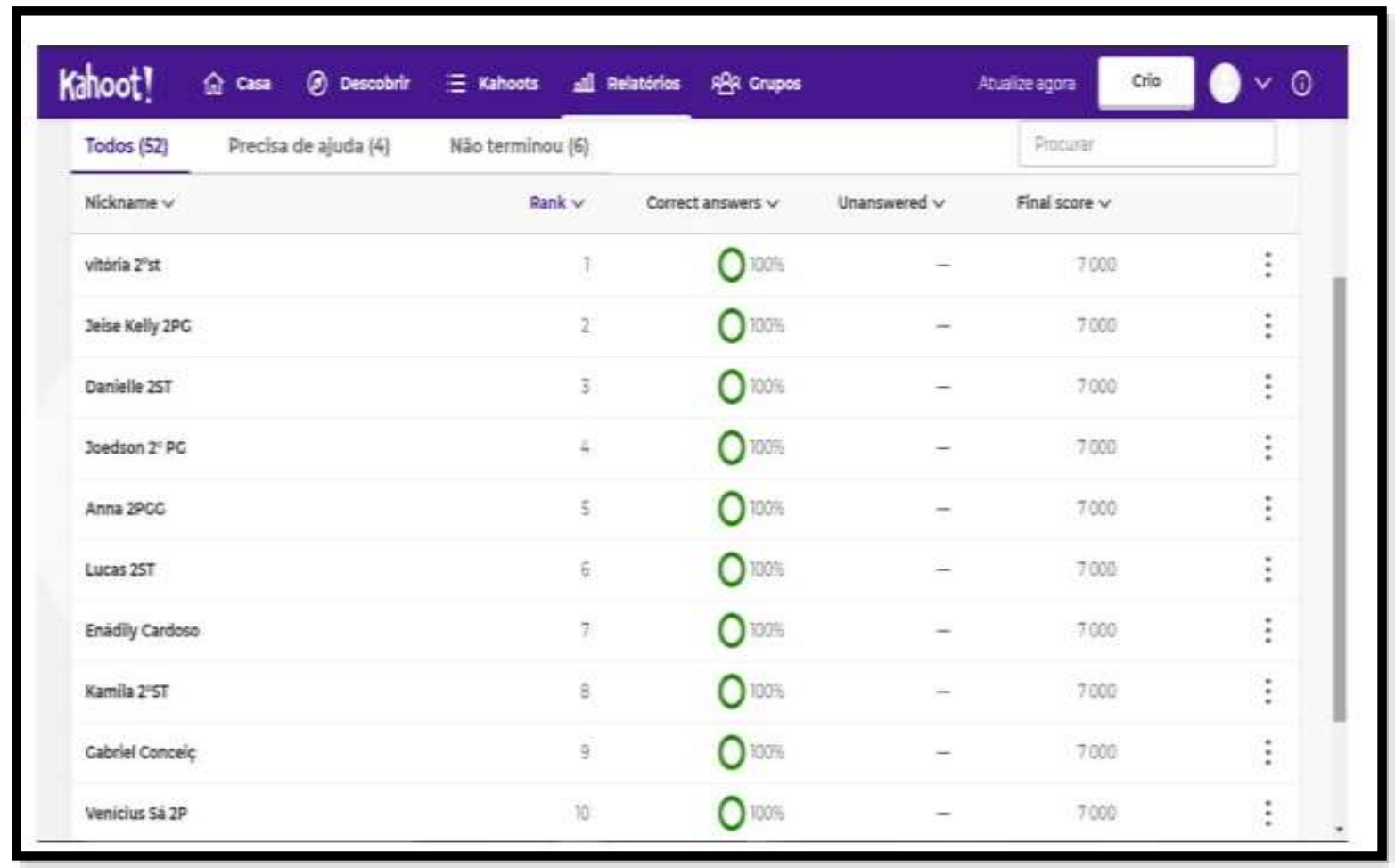

Fonte: Autoria própria. 
Rev. Científica Evidência, Maceió, v. 3, n.1, p. 108-124, out/dez, 2020

Quadro 5: Resultados com a porcentagem dos 10 primeiros nas $3^{\mathrm{a}}$ séries.

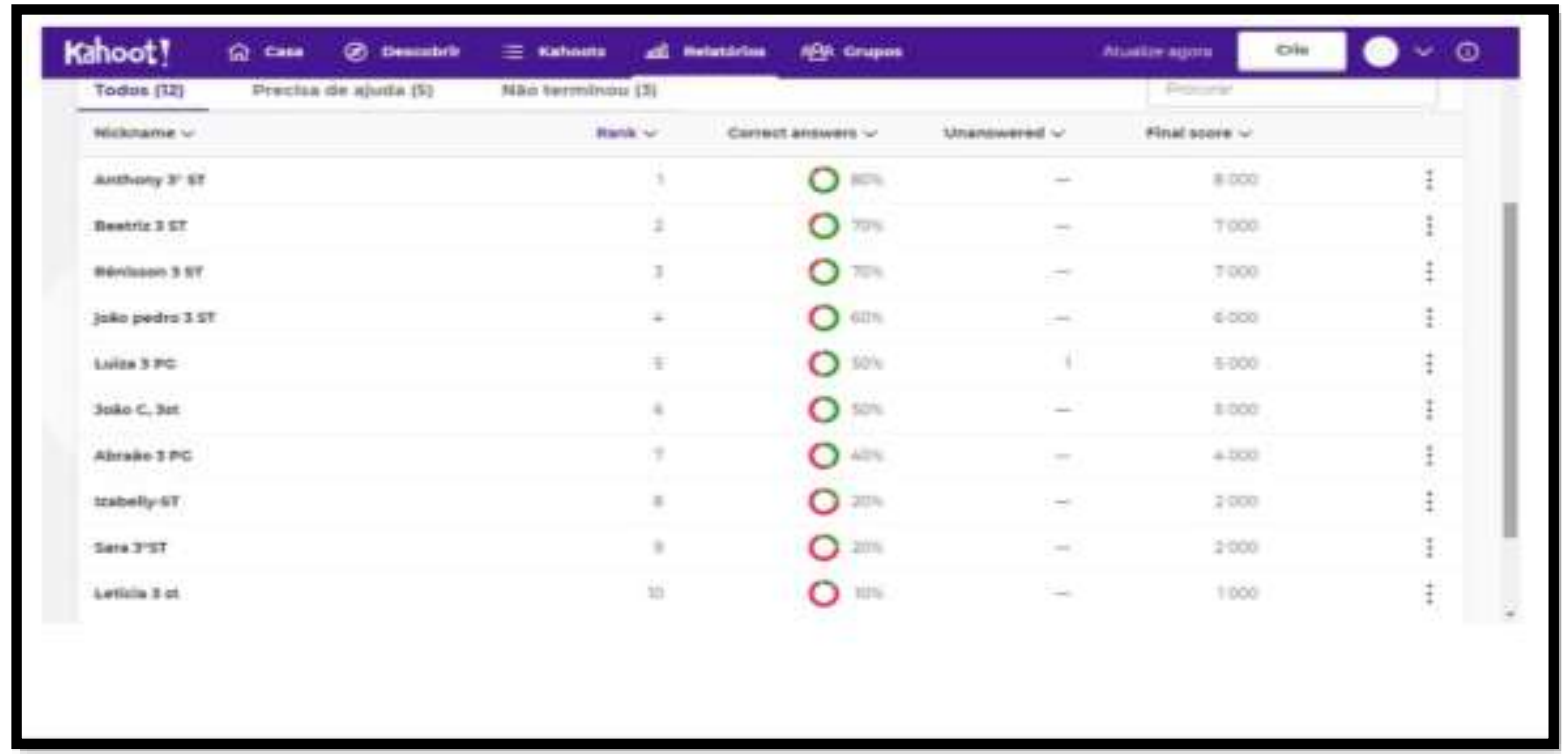

Fonte: Autoria própria.

Quadro 6: Alguns comentários dos estudantes e repercussão dos simulados e APP por turma.
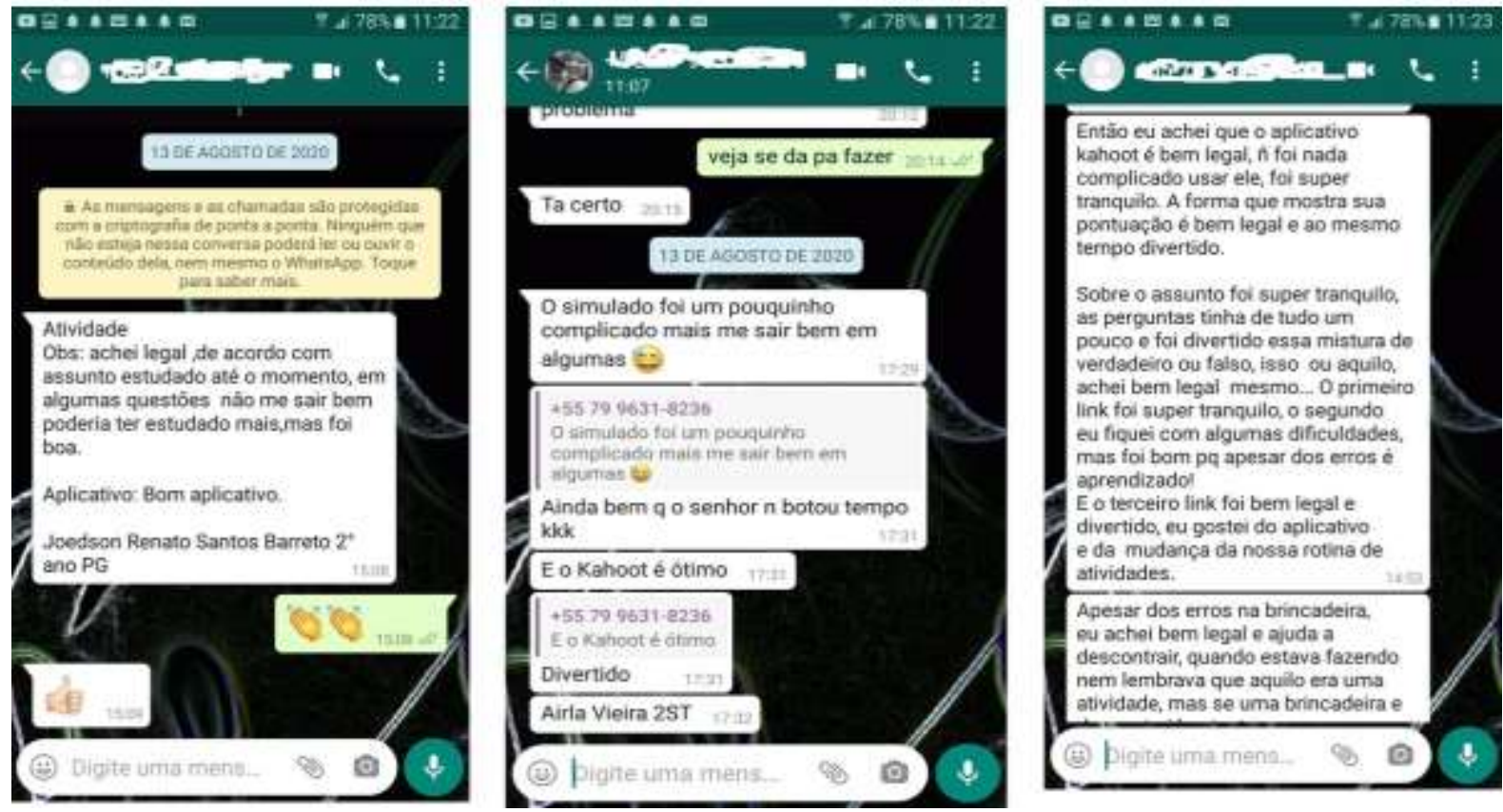

Fonte: Autoria própria. 
Quadro 7: Opinião dos alunos à respeito do simulado e APP
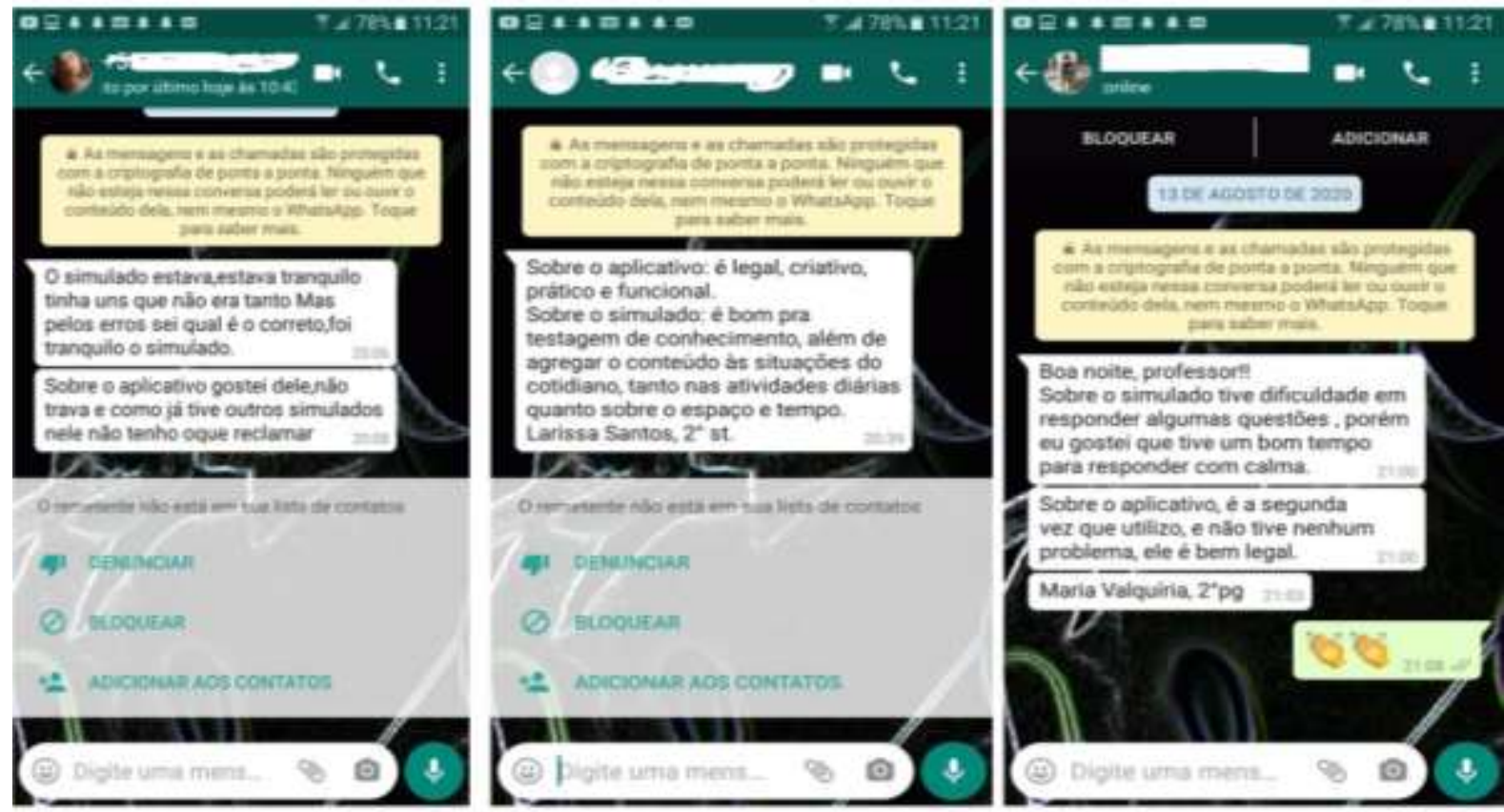

Fonte: Autoria própria.

Quadro 8: Opinião dos alunos à respeito do simulado e APP.
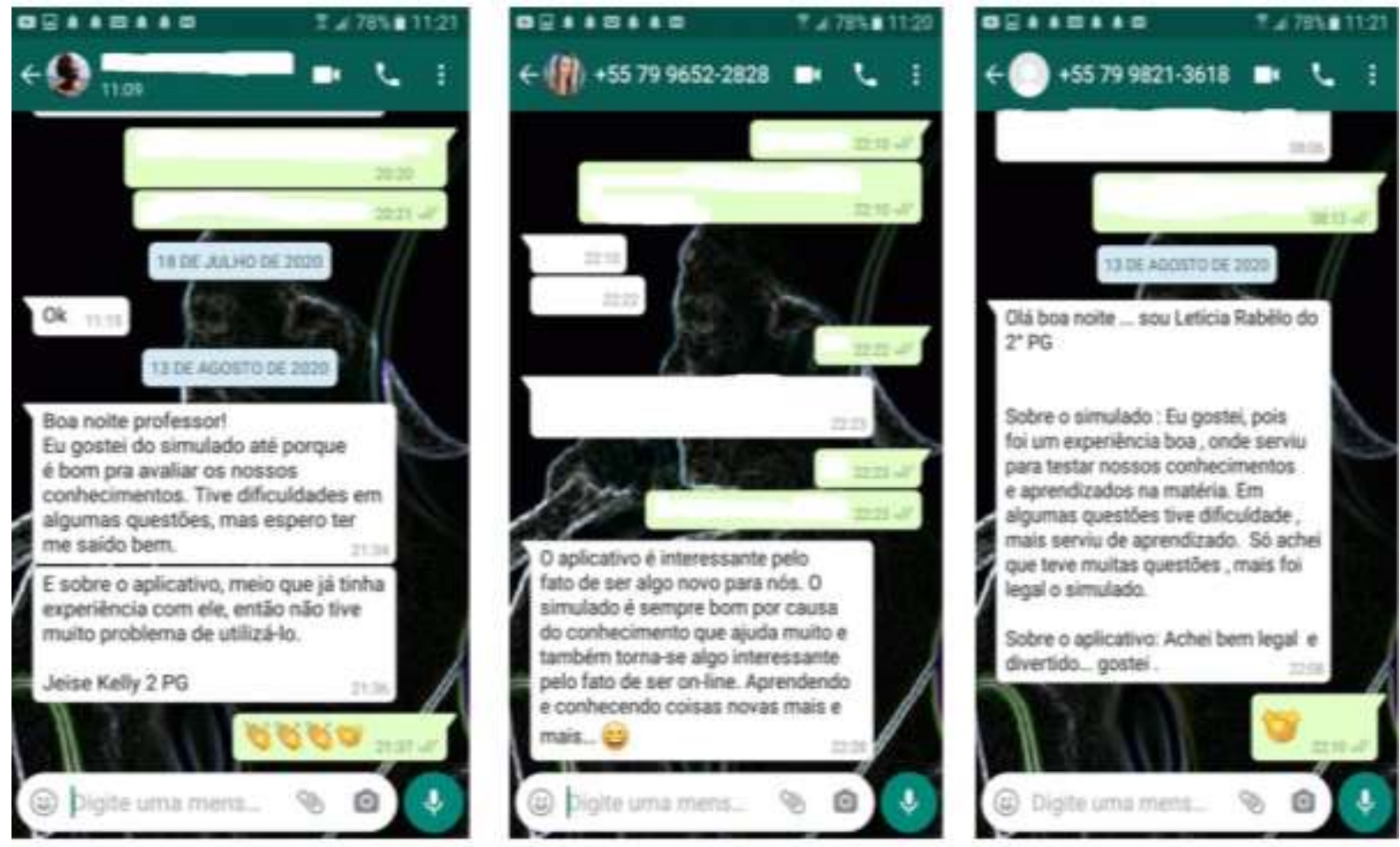

Fonte: Autoria própria. 
Quadro 9: Opinião dos alunos à respeito do simulado e APP.
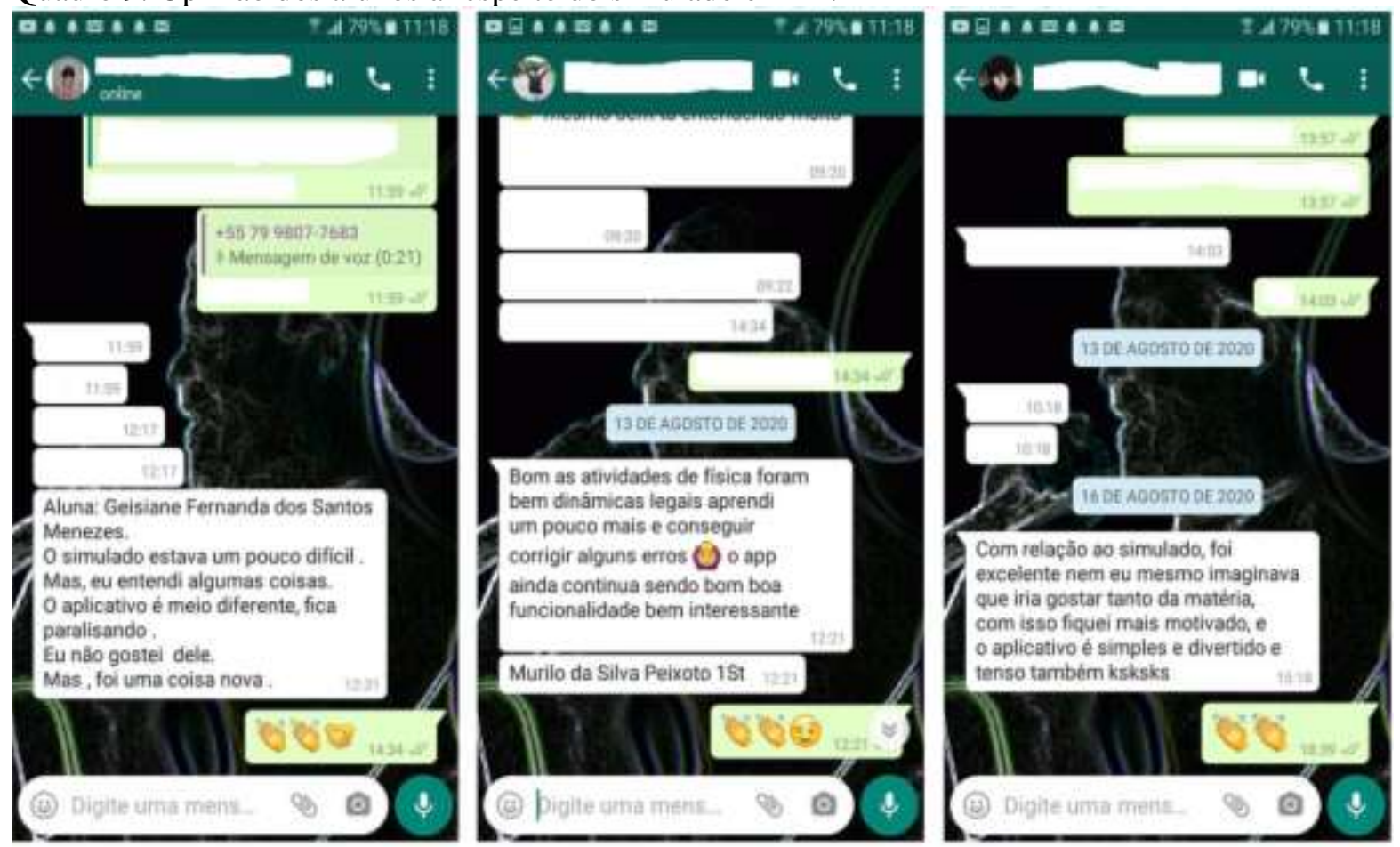

Fonte: Autoria própria.

\section{RESULTADOS E DISCURSÕES}

Aqui encontramos o resultado da relevância que o app deu a disciplina na busca por dinamizar a participação dos estudantes e como o aplicativo tinha sido dimensionado, vendo as suas proporções nas atividades dos alunos e a partir de 10 perguntas realizadas vimos a relevância e aproveitamento que adquiriram nesses moldes. Vejamos a primeira que tratamos sobre a percepção da ferramenta como método avaliativo:

Quadro 10: Resultados em relação a percepção da ferramenta kahoot como método avaliativo.

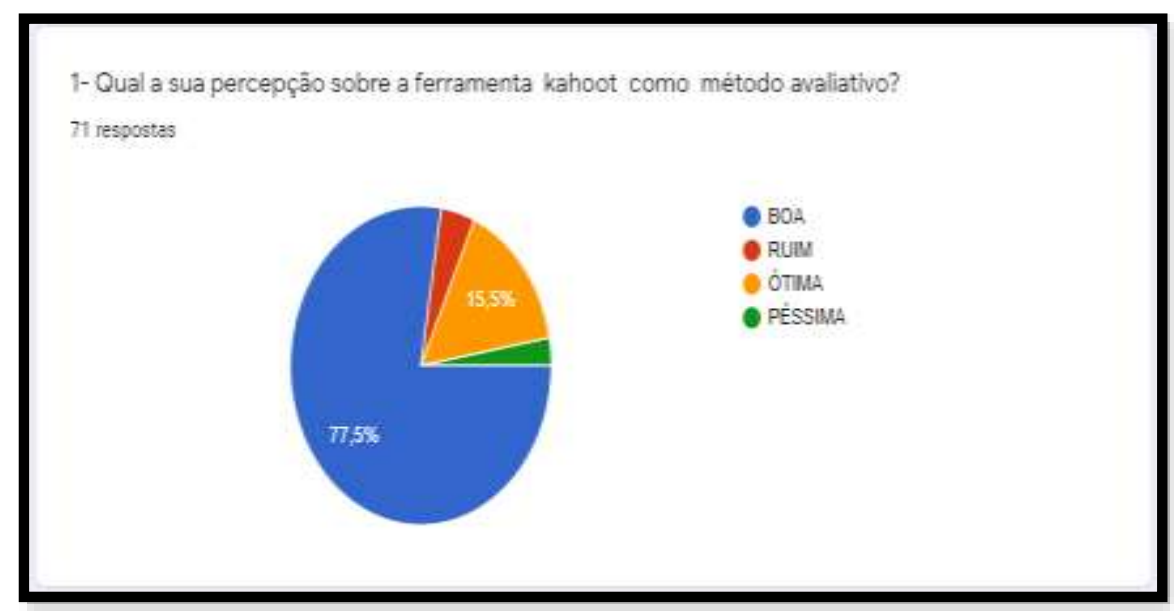

Fonte: Autoria própria. 
Os resultados apresentados ideia simplista é relevante e aceitável tendo repercutem na ideia de que os alunos que $71,8 \%$ dos estudantes dizem não ter tiveram uma boa aceitação do app cabendo nenhum desconforto no uso do APP como a $77,5 \%$ destes diz ter uma boa impressão forma avaliativa, nos atribuindo as dele como forma de avaliação. melhores ideias de que o aplicativo tem uma $\mathrm{Na}$ segunda pergunta tratamos do grande relevância em sua aplicação com os desconforto em usá-lo como estratégia jovens estudantes.

avaliativa e ainda assim observamos que a

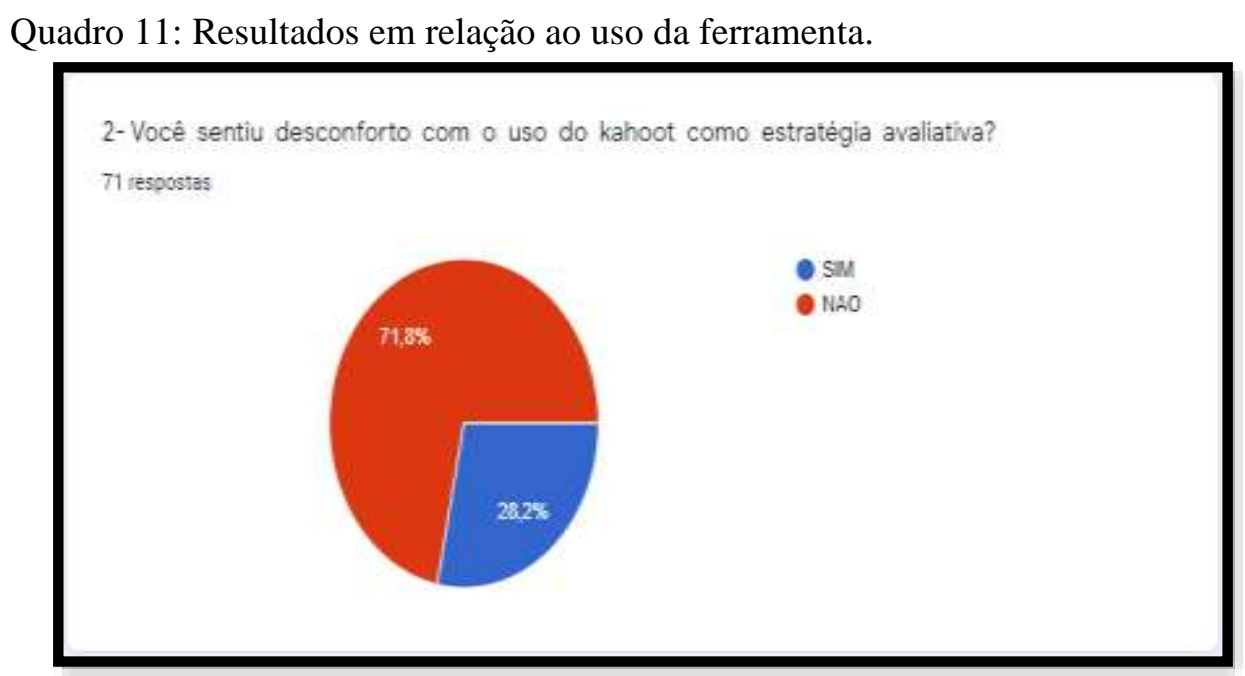

Fonte: Autoria própria.

Quadro 12: Resultados em relação ao tempo na utilização da ferramenta.

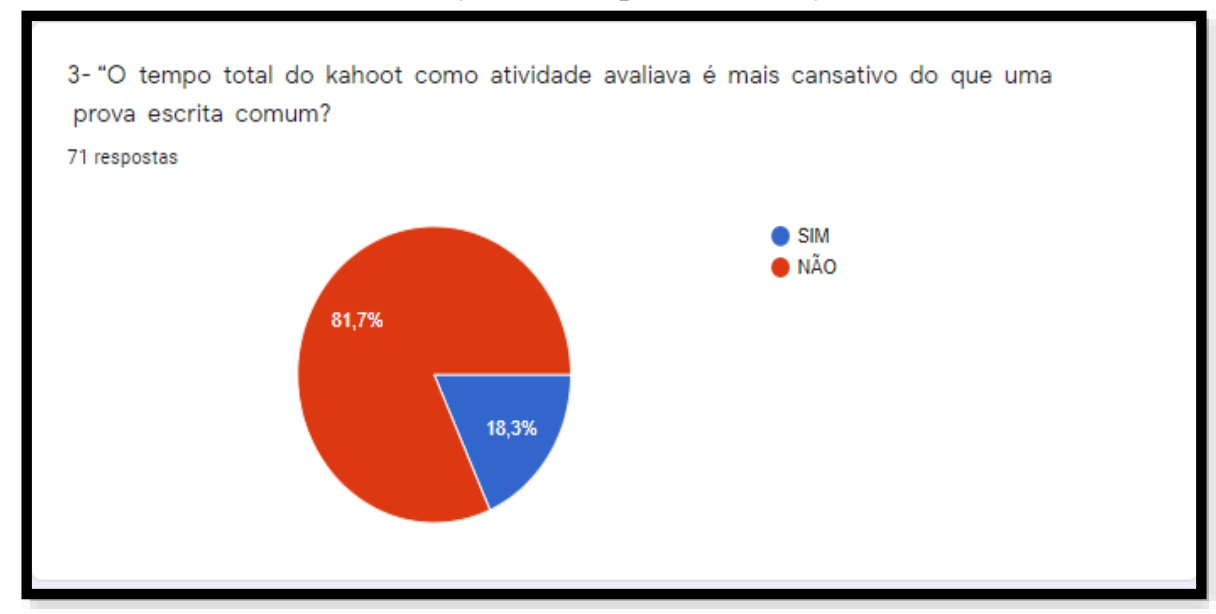

Fonte: Autoria própria.

O resultado apresentado é bastante de ensino/aprendizagem e $81,7 \%$ dos animador frente a outras formas tradicionais

estudantes disseram não possuir queixas do 
tempo necessário para realização, que se enquadra nos mesmos moldes das avaliações tradicionais. A questão 5 engloba alunos "fraudulentos" durante o uso do app pra realizar uma atividade e tão logo vemos a sua repercussão frente as respostas dos

necessariamente ao uso de métodos

Quadro 13: Resultados em relação a pergunto referente ao quadro abaixo.

5- EM ALGUM MOMENTO NA UTILIZAÇÃO DO KAHOOT VOCÊ USOU ALGUM TIPO DE COLA PARA RESPONDER AS QUESTÕES PROPOSTAS?

71 respostas

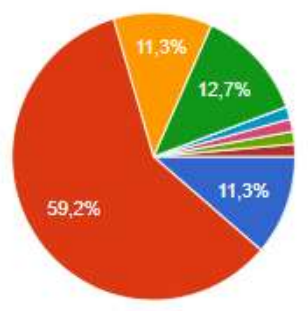

- SIM

- NÃO

- APENAS 1 VEZ

algumas Veses

- SEMPRE QUE POSSO

Já consultei o assunto no class

apenas calculadora

Eu utilizo os conteúdos trabalhados no

caderno.

- Pergunto a resposta de alguma quest.

Fonte: Autoria própria.

As respostas dos estudantes são propicias a realidade que nos convém e mesmo em distanciamento social eles usam as mais diversas facetas para se dar bem durante a realização da atividade

A sexta questão trazemos a empatia do estudante sobre a aplicação do simulado com o app e é interessante notar que mesmo diante do processo tecnológico de aprendizagem alguns ainda se mantém resistente as novas possibilidades de atividades.

Quadro 14: Resultados em relação a pergunto referente ao quadro abaixo.

6- Com relação ao simulado virtual, realizado pelo APP - Kahoot o que você achou?

71 respostas

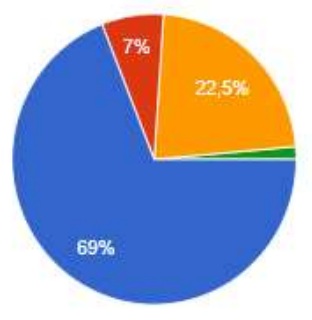


Cabendo a $69 \%$ deles terem uma boa impressão dos simulados virtuais realizados a cada final de mês com o app. Enquanto que 22,5 destes estudantes acham ótima a utilização, dando uma ótima repercussão para sua utilidade.
Nesta sétima pergunta, queríamos saber se a internet dos estudantes era suficiente para o uso do app e a realização do simulado podemos perceber o seguinte no quadro 15.

Quadro 15: Resultados em relação a internet.

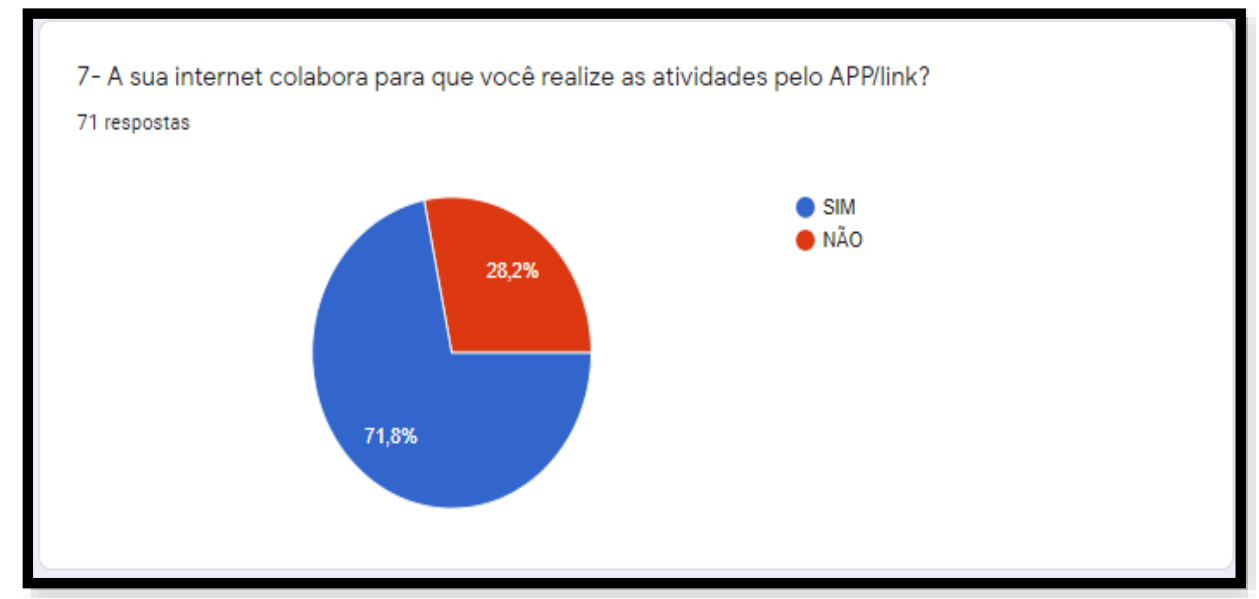

Fonte: Autoria própria.

Das 71 pessoas que responderam o questionário $71,8 \%$ dizem que a internet funciona muito bem, mesmo em dias atípicos, sendo que 28,2\% deles relataram que não e muitas vezes nos dias atípicos são os piores possíveis para as aulas remotas

Quadro 16: Resultados em relação a avaliação da ferramenta.

8- Como vc avalia as aulas remotas?

71 respostas

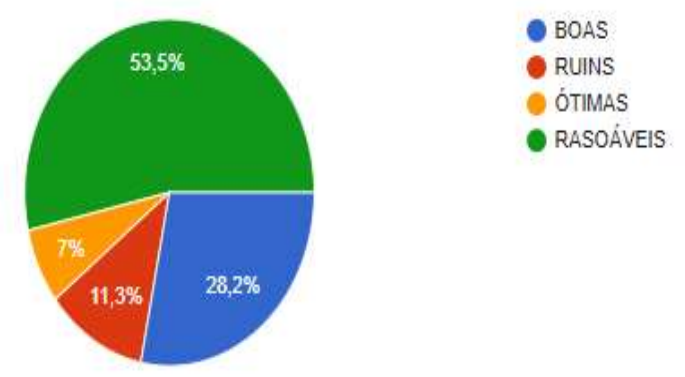

Fonte: Autoria própria. 
Nesta nona pergunta, gostaríamos de saber como eles avaliavam as aulas remotas de física e observamos o seguinte:

Quadro 16: Resultados em relação as aulas remotas.

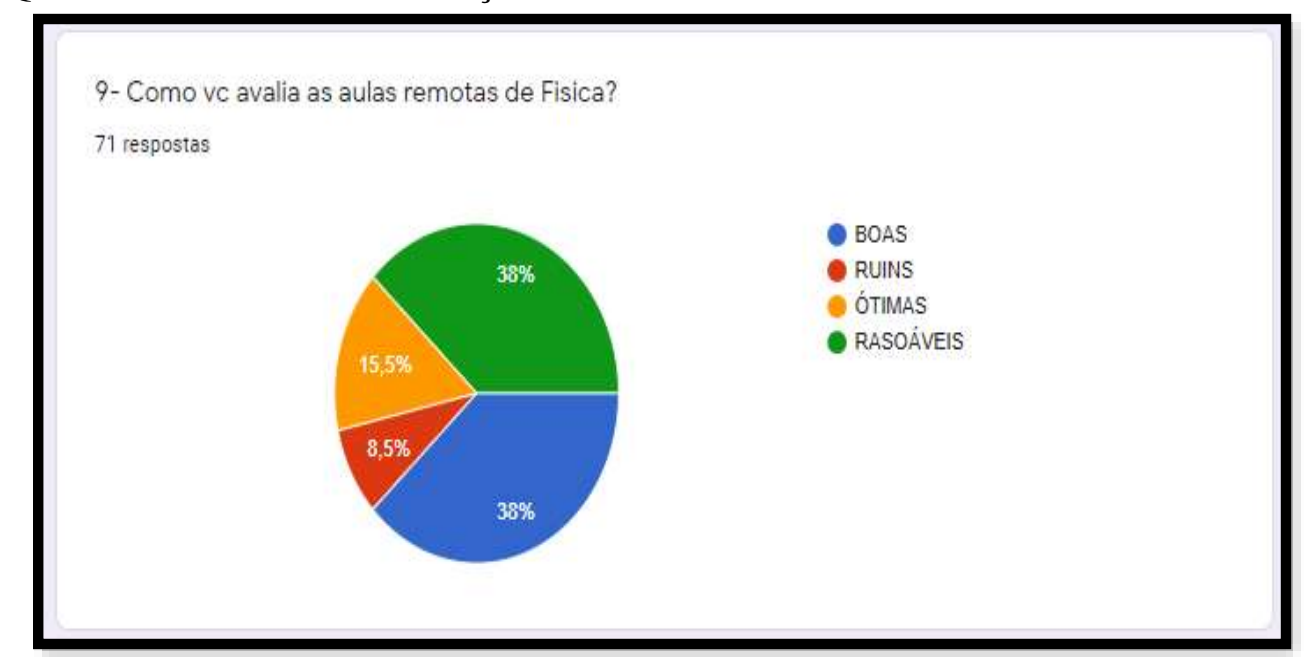

Fonte: Autoria própria.

Frente as alternativas propostas observamos que os estudantes estão se esforçando o máximo que podem no entendimento e compreensão das aulas remotas de física, mesmo não tendo um acompanhamento suscetível de contato e diálogos diretos. Nesse resultado achamos conveniente que as aulas estejam possibilitando aprendizado de alguma forma havendo um empate técnico onde $38 \%$ dos alunos acham as aulas remotas boas/ ou razoáveis frente a repercussão dos demais.

Nesta última pergunta, pedimos aos estudantes que deixassem um comentário para melhoramento das aulas remotas de física e a segui vemos o resultado. Não poderíamos esperar melhores respostas, sendo que os estudantes externaram suas ideias e dilemas frente as outras disciplinas, que convenhamos devem usar algum instrumento que os deixem entretidos e familiarizados com os conteúdos 
Quadro 16: Comentários relacionados a utilização das ferramentas.

10- DEIXE UM COMENTARIO DO QUE PODEMOS MELHORAR E UTILIZAR NAS PROXIMAS AULAS REMOTAS

71 respostas

\section{Quanto as aulas de fisica acho que 0}

proressor deveria continuar utilizando os videos do canal ciência todo dia já que o conteúdo é mais

dinâmico, porque alguns outros videos de outros canais que ele escolhe acabam com uma qualidade não muito boa ou os professores nos videos não explicam tão bem quanto o Pedro Loos do ciência todo dia, e após os vídeos acho que o professor deveria pegar algumas questões e resolver com a gente para que ficasse mais fácil a compreensão.

Atividades online que são mas rápido pra responder, do que passada por caderno, pois com tantas pra copiar,atrasar a gente.

na verdade, eu acho que os prefessores estao fazendo o melhor possivel,mas $\mathrm{n}$ e o mesmo que uma aula presencial

Pra mim tá tudo ótimo precisa melhorar nada não

Gosto bastante da dinâmica, continue assim!!

Diminuir as atividades, tem muuita atividade e as vezes acumula, só pq todo mundo ta em casa não significa q vamos ter tempo para fazer tooodas as atividades e ainda revisar o assunto mesmo dando uma semana para entregar, não estou falando especificamente de física mas sim de todas as matérias. fora isso mais nd

O tempo que temos pra responder os simulados é confortável, então eu acredito que tá bem legal dessa forma!

Fonte: Autoria própria.

\section{CONSIDERAÇÕES FINAIS}

Durante nossos estudos foi percebido um comportamento mais diferenciado dos estudantes e a quantidade de participação superou a expectativa das aulas remotas visto que a maioria deles não possuem internet, ficando sujeito a fazer as atividade muitas vezes reféns de dados móveis, mas mesmo assim percebemos que a quantidade de participantes são expressivamente superior que nas aulas remotas pelos links disponibilizados, não cabe aqui dizermos que o uso da ferramenta 
é a melhor que existe, mas apontamos como uma das que podem ser utilizada como ponto de partida para deixar o aluno mais atento as aulas remotas, pois a interação dos alunos com a nova estratégia foram bem

\section{REFERÊNCIAS}

LAGARTO et al. Guia de boas práticas de ensino online em contexto de emergência para alunos surdos durante a pandemia da doença covid- 19. Guidelines 2020 para Ministério da educação/ direção-geral da educação. Universidade católica portuguesa: Instituto de Ciências da Saúde Faculdade de Ciências Humanas Disponível em:<

https://www.dge.mec.pt/sites/default/files/ guia_de_boas_praticas_de_ensino_online_ em_contexto_de_emergencia_para_alunos _surdos_durante_a_pandemia_da_doenca_ covid_19.pdf $>$ Acesso em: 01 de out. de 2020 . perceptíveis e aceitável, sendo que alguns tiveram a tão esperada recusa que já prevíamos com coisa "nova" inserida na disciplina durante esse tempo de distanciamento e estudos remotos.

NOGUEIRA, F. Ensino remoto: o que aprendemos e o que podemos mudar nas práticas políticas públicas. Disponível em:<https://porvir.org/ensino-remoto-oque-aprendemos-e-o-que-pode-mudar-naspraticas-e-politicas-publicas/22 de junho de 2020> Acesso em: 28 de set. de 2020.

SILVA, J. B. et al. Tecnologias digitais e metodologias ativas na escola: o contributo do Kahoot para gamificar a sala de aula.

IFCE - Instituto Federal de Educação, Ciência e Tecnologia do Ceará, Fortaleza/CE - Brasil. Revista Thema, ENSAIOS E RELATOS. 2018 | Volume 15. nº. 2, Pág. 780 a 791. 